\title{
Assessment of hip muscles using surface EMG in gait analysis
}

\author{
Menekşe Karahan (D), Bülent Sabri Cığalı \\ Department of Anatomy, School of Medicine, Trakya University, Edirne, Turkey
}

\begin{abstract}
Objectives: The rectus femoris muscle flexes the thigh, while the gluteus maximus muscle extends it. Understanding the activations of these two muscles that function in opposition to each other during walking facilitates the interpretation of gait pathologies. The aim of this study was to evaluate the activations of these muscles during walking by using the surface electromyography (EMG) technique.

Methods: Twenty female volunteers aged 18-26 years participated in our study. The electrical activation of the rectus femoris and gluteus maximus muscles of the participants was simultaneously evaluated by gait analysis. At the same time, spatiotemporal parameters and phase parameters were obtained.

Results: The activation pattern of both muscles was found to be similar. Both muscles reached the highest activation in the swing phase. The lowest activation was also seen in the pre-swing phase. Both muscles were observed to be active in the loading and single-limb support phases.
\end{abstract}

Conclusion: The fact that these two antagonists muscles are active at the same time suggests that one is functioning concentrically, while the other eccentrically. Thus, stabilization of hip joint is provided when the body moves forward.

Keywords: gait analysis; gluteus maximus; rectus femoris; surface EMG

Anatomy 2020;14(2):86-90 @2020 Turkish Society of Anatomy and Clinical Anatomy (TSACA)

\section{Introduction}

Although observational evaluation of gait during daily life activities gives us some idea, the human eye cannot fully perceive many movements within milliseconds. In addition, the force, moment and muscle activities that occur while walking cannot be evaluated visually. ${ }^{[1,2]}$ Normal walking mechanism must be known and distinguished from the abnormal one for explaining some pathological conditions related with gait. The actual cause that disrupts gait and the supporting actions taken to compensate for this condition should also be understood. Recent studies suggest using systems that record all the components of gait by converting them into numerical data for to evaluate the efficacy of treatment. ${ }^{[1-4]}$ Gait analysis is an analysis technique that plays a role in the diagnosis and follow-up of many clinical cases. The electrical activation of the mus- cles during gait analysis can be evaluated by using electromyography (EMG).

The gluteus maximus (GM) extends the thigh, while the rectus femors (RF) flexes it. Understanding the activations of these antagonistic muscles during walking allows correct interpretation of pathological conditions and outcome of treatment. For this reason, the aim of this study was to record the EMG signals of these muscles during walking in young adults using a surface EMG device and to evaluate the activations of these muscles during the gait phases.

\section{Materials and Methods}

Twenty females aged 18 and 26 years with a body mass index (BMI) between 18.5 and 25 participated in our study. The ethical permission was given by the Scientific

This study is based on the Menekse Karahan's master thesis "Evaluation of hip muscles with surface emg in gait analysis". This study was a poster presentation at XXIV International Symposium on Morphological Sciences (2nd-6th September 2015, Istanbul, Turkey). 
Research Ethics Committee of Trakya University, School of Medicine before starting the study (Ethical permission date: 17/07/2013, number: TUTF-GOKAEK 2013/132). Those with permanent locomotor system disorders and any physical trauma within the last year were not included in the study. Volunteers participated to the study after signing the "Voluntary Informed Consent Form".

The gait analysis was conducted in the motion analysis laboratory of the Department of Anatomy of Trakya University, School of Medicine, Edirne, Turkey. The "Zebris ${ }^{\circledR}$ Force Measurement System" was used for the measurements. The software called "WinFDM", which is compatible with the device, was used to display the measurement results and to convert them into digital data.

The EMG device used in the measurements had 8 ana$\log$ channels and 4 digital channels. The power supply was 4 pcs of AAA $1.5 \mathrm{~V}$ battery. The device measured the electrical activity coming from the muscles and transfered it to the computer environment via bluetooth. The electrodes used for the measurement were disposable, self-adhesive silver/silver chloride $(\mathrm{Ag} / \mathrm{AgCl})$ dual electrodes. The diameter of the electrodes was $1 \mathrm{~cm}$ and the distance between their centers was $2 \mathrm{~cm}$.

The regions of bilateral GM and RF where the electrodes will be placed were selected in accordance with the criteria of "Surface electromyography for the non-invasive assessment of muscles" (SENIAM). In order to reduce skin impedance, the electrode areas of the skin were shaved and wiped with alcohol-soaked cotton. The EMG device was fixed to the participant's waist with the help of Velcro. The electrodes were placed, and the cables were fixed with a patch to prevent the electrode cables from creating noise that would interfere with the signal during movement. The reference electrode was placed on the tibial tuberosity. After the placement of the electrodes, the participants waited 3 minutes without moving for to allow the receiver surface to fully attach to the skin. Than the participants were asked to walk at a daily walking speed on the walking path (about $4.5 \mathrm{~m}$ ), which consisted of two force platforms and a wooden block at the same height with these platforms. The recording was taken from a single platform and the participants were not told from which it was taken.
The participants were allowed to take as many trial walks as they wanted to make it easier to adapt to the study. The device was calibrated before each procedure. Each participant was asked to walk three times on the platform.

Since the EMG signal amplitude can be easily affected by recording conditions and individuals, a reference value is determined for each individual. The electrical activity value that arises during the maximum voluntary contraction is selected as the reference value. ${ }^{[5,6]}$ Thus, the contribution of the functional capacity of the muscle was determined according to this reference value. Another suggestion in the literature was to use the peak value of the EMG amplitude as a reference value. ${ }^{[6]}$ Accordingly, the peak value in EMG signal was taken as reference and calculated separately for each individual. The mean and standard deviation of the data collected from all subjects were calculated. In addition, the activations of the muscles on the right and left sides were compared.

Statistics were carried out using SPSS for Windows (Version 20.0, Chicago, IL, USA). Data were expressed as mean \pm standard deviation (SD). "One-sample Kolmogorov Smirnov Test" was used to control normality of the variables, and the "Wilcoxon signed-rank test" was used to compare significance between individual differences; $\mathrm{p}<0.05$ was considered statistically significant.

\section{Results}

The mean age of the participants was $20.6 \pm 1.81$ years, the mean height was $162.25 \pm 5.83 \mathrm{~cm}$, the mean weight was $56.8 \pm 4.92 \mathrm{~kg}$.

The mean values of time-distance parameters and phase parameters obtained from the gait analysis were given in Tables 1 and 2 respectively.

The GM was active in all phases. There was a significant increase in the activation of the left side in the swing phase $(p<0.05)$. There was no difference between the other phases in terms of activation. The lowest activation was seen in the pre-swing phase, while the highest activation was seen in the swing phase, but the difference was not statistically significant $(\mathrm{p} \geq 0.05)$. There was no significant difference between the activations of the right and left side muscles $(\mathrm{p} \geq 0.05)$. The activation was symmetrical (Table 3$)$.

Table 1

Spatio-temporal parameters.

\begin{tabular}{cccccc} 
& SW & SL & C & V & TDS \\
\hline Mean \pm SD & $6.20 \pm 3.10$ & $113.95 \pm 12.11$ & $51.50 \pm 4.21$ & $3.55 \pm 0.51$ & $27.60 \pm 2.37$ \\
\hline
\end{tabular}

C: cadance (strides/min); SL: stride length (cm); SW: step width (cm); TDS: total double support (\%); V: velocity $(\mathrm{km} / \mathrm{h})$. 
Table 2

Phases of gait cycle.

\begin{tabular}{|c|c|c|c|c|c|c|c|c|c|}
\hline \multicolumn{8}{|c|}{ Stance phase } & \multirow{2}{*}{\multicolumn{2}{|c|}{$\begin{array}{c}\text { Swing phase } \\
\text { Total (\%) }\end{array}$}} \\
\hline \multicolumn{2}{|c|}{ LR (\%) } & \multicolumn{2}{|c|}{ SS (\%) } & \multicolumn{2}{|c|}{ PS (\%) } & \multicolumn{2}{|c|}{ Total (\%) } & & \\
\hline $\mathbf{L}$ & $\mathbf{R}$ & $\mathbf{L}$ & $\mathbf{R}$ & $\mathbf{L}$ & $\mathbf{R}$ & $\mathbf{L}$ & $\mathbf{R}$ & $\mathbf{L}$ & $\mathbf{R}$ \\
\hline $13.43 \pm 1.41$ & $14.08 \pm 1.79$ & $35.90 \pm 2.53$ & $36.7 \pm 2$ & $14.1 \pm 1.58$ & $13.45 \pm 1.19$ & $63.46 \pm 3.42$ & $64.39 \pm 1.8$ & $36.55 \pm 3.42$ & $35.65 \pm 1.81$ \\
\hline
\end{tabular}

L: left side; LR: load response; PS: preswing; R: right side; SS: single support.

The lowest activation of the RF was in the pre-swing phase, while the peak activation was seen in the swing phase, but the difference was not statistically significant $(p \geq 0.05)$. There was no significant difference between the right and left sides $(\mathrm{p} \geq 0.05)$ (Table 4$)$.

\section{Discussion}

The most important findings of the present study were that activations of GM and RF were similar and these two muscles were active in each phase of gait. Particularly, the activation of the RF during gait has been the subject of many scientific studies, but no consensus has been reached. Although the reason for the different results was attributed to the different test techniques (surface electrodes or wire electrodes), there are also differences in the studies conducted using the same technique.

In studies using surface electrodes, RF activation has shown triphasic and biphasic patterns. In general, the highest activation was observed at the beginning of the stance phase. ${ }^{[7-12]}$ In studies using wire electrodes, the

Table 3

EMG activation of gluteus maximus.

\begin{tabular}{lccccc} 
& & & & & \\
& Left & Right & $P$ (left) & $P$ (right) & $P$ (Left-Right) \\
\hline LR & $1.95 \pm 0.759$ & $2.1 \pm 0.718$ & $P 1=0.36$ & $\begin{array}{l}P 1=0.903 \\
P 3=0.425\end{array}$ & $P=0.572$ \\
\hline SS & $2.3 \pm 0.733$ & $2.25 \pm 0.786$ & $P 3=0.394$ & $P 4=0.705$ & $P=0.782$ \\
& & $P 5=.692$ & $P 5=0.744$ & $P=0.272$ \\
\hline PS & $1.6 \pm 0.754$ & $1.85 \pm 0.813$ & $P 2=0.645$ & $P 2=0.530$ & $P=1.000$ \\
\hline SP & $2.9 \pm 0.308$ & $2.9 \pm 0.308$ & $* P 6=0.012$ & $P 6=0.560$ & \\
\hline
\end{tabular}

GM: gluteus maximus; LR: load response; PS: preswing; P1: comparison of LR and SS; P2: comparison of LR and PS; P3: comparison of LR and SP; P4: comparison of SS and PS; P5: comparison of SS and SP; P6: comparison of PS and SP; SS: single support.

Table 4

EMG activation of rectus femoris.

\begin{tabular}{|c|c|c|c|c|c|}
\hline & \multicolumn{5}{|c|}{ RF } \\
\hline & Left & Right & $P$ (left) & P (right) & P (Left-Right) \\
\hline LR & $2.60 \pm 0.681$ & $2.25 \pm 0.851$ & $\begin{array}{l}P 1=0.795 \\
P 3=0.063\end{array}$ & $\begin{array}{l}P 1=0.937 \\
P 3=0.692\end{array}$ & $P=0.232$ \\
\hline SS & $2.40 \pm 681$ & $2.5 \pm 0.688$ & $\begin{array}{l}P 4=0.230 \\
P 5=0.536\end{array}$ & $\begin{array}{l}P 4=0.465 \\
P 5=0.352\end{array}$ & $P=0.480$ \\
\hline PS & $1.90 \pm 0.788$ & $1.60 \pm 0.754$ & $P 2=0.413$ & $P 2=0.324$ & $P=0.222$ \\
\hline SP & $2.70 \pm 0.470$ & $2.65 \pm 0.587$ & $P 6=0.444$ & $P 6=0.723$ & $P=0.782$ \\
\hline
\end{tabular}

LR: load response; PS: preswing; P1: comparison of LR and SS; P2: comparison of LR and PS; P3: comparison of LR and SP; P4: comparison of SS and PS; P5: comparison of SS and SP; P6: comparison of PS and SP; RF: rectus femoris; SS: single support. 
activation showed a biphasic pattern. ${ }^{[13,14]}$ The studies comparing superficial and wire electrodes reported different peak numbers and phases of the peaks. ${ }^{[15,16]}$ Byrne et al. ${ }^{[17]}$ concluded that the surface electrode was not suitable for recording the activation of the RF. The reason why the data recorded with these surface and wire electrodes are different is that the surface electrodes are more sensitive to the sounds coming from the adjacent muscles.

In our study, we found that activation of the RF was particularly high in the loading, single-limb support and swing phases. Its activation began to increase during the transition from the pre-swing phase to the swing phase in most of the subjects. Likewise, there was an increase during the transition from the loading phase to the singlelimb support phase. These triphasic results are consistent with the study by Nymark et al. ${ }^{[9]}$ but the sizes of the bursts are different. The activation in the swing phase is consistent with the results of studies conducted with superficial and wire electrodes. ${ }^{[5,6,13,15,17]}$

We found an activation in the RF in the loading phase, but there are very different results about this in the literature. There is not much information on the activation time of the RF during walking but the relationship between speed and activation has been compared. Barlett et al. ${ }^{[18]}$ examined the GM in two parts, upper and lower. They found that the the upper part start contraction at the beginning of the stance phase and at the end of the swing phase. They also found the lower part start contraction in the same phases but the activation was slightly lower than the activation of the upper part. Wall-Scheffler et al. ${ }^{[19]}$ found the activation of the GM to be highest at the beginning of the stance phase. They observed that the activation was lowest in the pre-swing phase, and the activation increased again at the end of the swing. This information reveal that the activation of GM was not reported as conflicting as the activation of the RF.

We analyzed the activation of bilateral GM in the present study. The activation patterns of the GM and RF were similar and no significant difference was found between two sides. The activation of the GM was high in the loading phase, single-limb stance phase and the swing phase. We found the lowest activation in the pre-swing phase. In vast majority of the participants, the activation started to increase during the transition from the stance phase to the swing phase. The highest activation was observed in the swing phase, the second one in the singlelimb stance phase, and the third one in the loading phase. This pattern is consistent with the results of WallScheffler et al. ${ }^{[19]}$
We observed the electrical activation patterns of the GM and RF to be similar. The phases in which both have the lowest and highest activation are the same. In addition, the activation sizes are close to each other. However, the GM is a hip extensor, while the RF is a thigh flexor. In this case, their activation at the same time may mean that while one functions concentrically, the other functions eccentrically. This activation can explain both controlled movement and maintaining the stabilization of the hip joint while moving the trunk forward.

There are some limitations for these kinds of studies. Gait parameters are affected by many conditions as well as change with age. We suggest that standart values can be obtained by conducting a study in different age groups in a larger sample.

\section{Conclusion}

The activation patterns of the RF and GM were found to be similar on surface EMG. The fact that these two antagonists muscles are active at the same time suggests that one is functioning concentrically, while the other eccentrically. Thus, stabilization of hip joint is provided when the body is moved forward. The data in the present study was obtained from healthy young females. Therefore, we suggest that this data can be used a guide for making comparative analysis to better understand pathological conditions.

\section{Conflict of Interest}

None of the authors has any conflicts of interest to declare.

\section{Author Contributions}

MK: data collection, analysis, literature review, writing; BSC: design, supervision, critical review.

\section{Ethics Approval}

The ethical permission was given by the Scientific Research Ethics Committee of Trakya University, Faculty of Medicine (Ethical permission date: 17/07/2013, number: TUTF-GOKAEK 2013/132).

\section{Acknowledgements}

We wish to thank all the study participants.

\section{Funding Statement}

This work was supported by TUBAP (Trakya University Scientific Research Projects Coordination Unit) (2013/ 156). 


\section{References}

1. Bozer C. Genç erişkinlerde günlük aktivite sırasında yapılan bazı hareketlerin kinetik analizi. Edirne: Trakya University; 2007. p. $1-123$.

2. Özaras N, Yalçın S, Yürüme Analizi. 1st ed. İstanbul: Avrupa Tip Kitapç1lık; 2001. p. 1-76.

3. Kanatlı U, Yetkin H, Songür M, Öztürk A, Bölükbaşı S. Yürüme analizinin ortopedik uygulamaları. TOTBID Dergisi 2006;5:53-9.

4. Gülçimen B, Ülkü S. İnsan ayağı biyomekaniğinin incelenmesi. Uludağ University Journal of the Faculty of Engineering 2008;13: 27-33.

5. Massó N, Rey F, Romero D, Gual G, Costa L, Germán A. Surface electromyography applications in the sport. Apunts Med Esport 2010;45:121-30.

6. Konrad P. The ABC of EMG: A Practical introduction to kinesiological electromyography. Scottsdale (AZ): Noraxon USA Inc.; 2005 p. 1-60.

7. Benedetti MG, Agostini V, Knaflitz M, Bonato P. Muscle activation patterns during level walking and stair ambulation. Applications of EMG in Clinical and Sports Medicine 2012;8:117-30.

8. Shiavi R, Bugle H, Limbird T. Electromyographic gait assessment, Part 1: Adult EMG profiles and walking speed. J Rehabil Res Dev 1987;24:13-23.

9. Nymark JR, Balmer SJ, Melis EH, Lemaire ED, Millar S. Electromyographic and kinematic nondisabled gait differences at extremely slow overground and treadmill walking speeds. J Rehabil Res Dev 2005;42:523-34.

10. Di Nardo, Fioretti S. Statistical analysis of surface electromyographic signal for the assessment of rectus femoris modalities of activation during gait. J Electromyogr Kinesiol 2013;23:56-61.

ORCID ID:

M. Karahan 0000-0002-1114-4478;

B. S. Cığalı 0000-0001-6317-4719

deomed.
11. Li L, Ogden LL. Muscular activity characteristics associated with preparation for gait transition. Journal of Sport and Health Science 2012;1:27-35.

12. Winter D, Yack H. EMG profiles during normal human walking: stride-to-stride and inter-subject variability. Electroencephalogr Clin Neurophysiol 1987;67:402-11.

13. Annaswamy TM, Giddings CJ, Della Croce U, Kerrigan DC. Rectus femoris: its role in normal gait. Arch Phys Med Rehabil 1999;80: 930-4.

14. Montgomery 3rd WH, Pink M, Perry J. Electromyographic analysis of hip and knee musculature during running. Am J Sports Med 1994; 22:272-8.

15. Barr KM, Miller AL, Chapin KB. Surface electromyography does not accurately reflect rectus femoris activity during gait: impact of speed and crouch on vasti-to-rectus crosstalk. Gait Posture 2010;32: $363-8$.

16. Nene A, Byrne C, Hermens H. Is rectus femoris really a part of quadriceps? Assessment of rectus femoris function during gait in able-bodied adults. Gait Posture 2004;20:1-13.

17. Byrne C, Lyons G, Donnelly A, O'keeffe D, Hermens H, Nene A. Rectus femoris surface myoelectric signal cross-talk during static contractions. J Electromyogr Kinesiol 2005;15:564-75.

18. Bartlett JL, Sumner B, Ellis RG, Kram R. Activity and functions of the human gluteal muscles in walking, running, sprinting, and climbing. Am J Phys Anthropol 2014;153:124-31.

19. Wall-Scheffler CM, Chumanov E, Steudel-Numbers K, Heiderscheit B. Electromyography activity across gait and incline: the impact of muscular activity on human morphology. Am J Phys Anthropol 2010; 143:601-11.

Correspondence to: Menekşe Karahan, PhD

Department of Anatomy, School of Medicine, Trakya University,

Balkan Campus, 22040, Edirne, Turkey

Phone: +90 2842357641 / 1510

e-mail: karahanmenekse@hotmail.com

Conflict of interest statement: No conflicts declared.

This is an open access article distributed under the terms of the Creative Commons Attribution-NonCommercial-NoDerivs 4.0 Unported (CC BY-NCND4.0) Licence (http://creativecommons.org/licenses/by-nc-nd/4.0/) which permits unrestricted noncommercial use, distribution, and reproduction in any medium, provided the original work is properly cited. How to cite this article: Karahan M, Cığalı BS. Assessment of hip muscles using surface EMG in gait analysis. Anatomy 2020;14(2):86-90. 